\title{
Effect of Heat Treatment of the Alumina Powder on the Microstructure and Properties of Coatings
}

\author{
Prozorova Mayya ${ }^{1, \text { a }}$, Kovaleva Marina ${ }^{1, \mathrm{~b}}$, Arseenko Marii ${ }^{\mathrm{a} \text {, c }}$, \\ Yapryntsev Maxim ${ }^{1,}$, , Novikov Vseslav ${ }^{1,}$, , Sirota Vyacheslav ${ }^{1, f}$ \\ Tyurin Yurii ${ }^{2, g}$, Kolisnichenko Oleg ${ }^{2, ~ h}$, Vasilik Nikolay ${ }^{3, i}$ \\ ${ }^{1}$ Belgorod National Research University, Pobedy 85, Belgorod, 308015 Russia \\ ${ }^{2}$ Paton Institute of Electric Welding, National Academy of Sciences of Ukraine, Kiev, 03650 Ukraine \\ ${ }^{3}$ N.N. Semenov Institute of Chemical Physics, RAS, Kosygina 4, Moscow, 117977, Russia
}

\begin{abstract}
The alumina powder was treated at a high temperature $\left(1000^{\circ} \mathrm{C}\right)$. Dense (porosity of less than $2 \%$ ), solid $(1280 \pm 30 \mathrm{HV} 0.3)$ and wear-resistant coatings based on heat-treated alumina powder were obtained by a multi-chamber detonation sprayer on the steel substrate. The microstructure, microhardness and the wear resistance of the alumina coatings were investigated.
\end{abstract}

\section{Introduction}

At the current stage of development of materials one of the most pressing tasks is to develop coatings with high hardness, wear resistance, heat resistance and insulating properties. The $\alpha-\mathrm{Al} 2 \mathrm{O} 3$ powder coatings obtained by the thermal methods of a raw material coatings are met all these requirements [1]. The cost of one kilogram of the powder based on $\alpha-\mathrm{Al} 2 \mathrm{O} 3$ is rather high that eventually affect the final cost of the finished product. A promising trend in the art is the use of an alumina powder in view of its low cost. The studies $[1,2]$ show that the coatings obtained from the raw material based on alumina, in many respects the above coating lose as alumina powder consists of a number of metastable crystallographic modifications, which eventually leads to a high porosity and brittleness, and to a lack of durability of the resulting coatings. It has previously been shown that metastable alumina phase transition to a stable $\alpha-\mathrm{Al} 2 \mathrm{O} 3$ by the heating [3]. As a rule, after the application of alumina coating, finished products are subjected to heat treatment to improve the strength characteristics of aluminum coatings. In the paper [4] observed that in order to obtain dense and hard ceramic coatings or films, the final product with alumina coating was subjected to heating at the temperature above $800{ }^{\circ} \mathrm{C}$. However, this process can lead to softening of the substrate material, which affects the quality of the finished product. From the foregoing it is apparent that thermal treatment of the alumina powder prior to its use as a coating material is most appropriate.

The purpose of this study is to investigate the microstructure and mechanical properties of the alumina coatings from the available raw materials after high temperature treatment, which was formed by a new power-saving multi-chamber detonation sprayer [5-7].

\section{Experimental Procedure}

Alumina powder (d (0.1): 3.50 micron, $d(0.5): 25.19$ micron, $\mathrm{d}(0.9)$ : 54.75 micron) was subjected to high temperature treatment. The particle size of alumina powder was measured by Analysette 22 NanoTec laser diffractometer. X-ray phase analysis shows that powder consists of $\gamma-\mathrm{Al} 2 \mathrm{O} 3$ (89.34\%), $\alpha-\mathrm{Al} 2 \mathrm{O} 3$ (5.96\%) and impurity phases of $\mathrm{TiO} 2$ (rutile $-4.7 \%$ ). Heat treatment was carried out on air using a LT 5/12/B180 furnace (Nabertherm $\mathrm{GmbH})$. The alumina powder were placed in the furnace and heated from 23 to $1000^{\circ} \mathrm{C}$ at rate of $5^{\circ} \mathrm{C} / \mathrm{min}$, then left for $3 \mathrm{~h}$ at $1000^{\circ} \mathrm{C}$ and then were allowed to cool to room temperature into the furnace.

The particle size of alumina powder after high temperature treatment was $d(0.1): 2.98$ micron, $d(0.5)$ : 21.16 micron, $\mathrm{d}(0.9)$ : 51.24 micron. X-ray phase analysis of the alumina powder after high temperature treatment showed that the powder consists of $\alpha-\mathrm{Al} 2 \mathrm{O} 3(65.44 \%), \delta$ $\mathrm{Al} 2 \mathrm{O} 3$ (30.46\%) and impurity phases of $\mathrm{TiO} 2$ (rutile 4.1\%). The Alumina powder after the high temperature treatment was used as the starting material to deposit a dense ceramic coatings on a plate with dimensions of $35 \times 35 \times 2 \mathrm{~mm}$ of the steel substrate $(\mathrm{C}-0.14-0.22$, $\mathrm{Si} \sim 0.05, \quad \mathrm{Mn}-0.3-0.6, \mathrm{Ni} \sim 0.3, \mathrm{~S} \sim 0.05, \quad \mathrm{P} \sim 0.04$, $\mathrm{Cr} \sim 0.3$, all in wt pct).

In the present study, a multi-chamber, vertically mounted, detonation sprayer (MCDS) [5-7] with a barrel length of $500 \mathrm{~mm}$ was employed to deposit the aluminum

\footnotetext{
aprozorova@bsu.edu.ru, ${ }^{b} k$ kovaleva@bsu.edu.ru, ${ }^{c}$ arseenko_m@bsu.edu.ru,

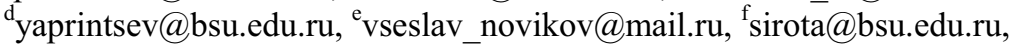

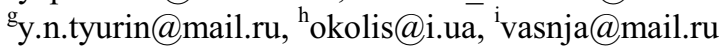


oxide powder coatings on steel substrates. The alumina coatings were prepared according to the parameter values presented in Table 1. A barrel with throat diameter of 16 mm was adopted. Flat specimens of steel were sandblasted by 25 A F360 alumina grits prior to spraying.

Table 1. Parameters for formation of ceramic coatings

\begin{tabular}{|c|c|c|c|c|}
\hline \multicolumn{2}{|c|}{ Flow rate of fuel mixture components, $\left(\mathrm{m}^{3} / \mathrm{h}\right)$} & \multirow{2}{*}{$\begin{array}{c}\text { Barrel } \\
\text { length, } \\
(\mathrm{mm})\end{array}$} & $\begin{array}{c}\text { Powder } \\
\text { feed rate, } \\
(\mathrm{g} / \mathrm{h})\end{array}$ \\
\hline Oxygen & $\begin{array}{c}\text { Propane }(30 \%) \\
+ \text { butane }(70 \%)\end{array}$ & Air & 500 & 500 \\
\hline$* 2.87 / * * 3.26$ & $* 0.54 / * * 0.65$ & $* 1.41 / * * 1.08$ & 500 \\
\hline *Cylindrical combustion chamber. ${ }^{* *}$ Disk combustion chamber \\
\hline
\end{tabular}

The microstructure and elemental composition of the powder and coatings were determined using scanning electronic microscopes Quanta 600 FEG (SEM) equipped with an X-ray detector of the PEGASUS 2000 system. Porosity was determined by the metallographic method with qualitative and quantitative analysis of pore geometry using an inverted optical microscope (Olympus GX51) [8]. Ten arbitrarily selected optical micrographs (bright field, $500 \times$ magnification) for each experimental point were registered using SIAMS Photolab software. X-ray diffraction analysis of the alumina powder and ceramic coatings was carried on the X-ray diffractometer (Rigaku Ultima IV) in the pseudo-parallel beam mode in an angle range of $18-100^{\circ} 2$-theta. Crystalline phases were identified using the ICDD PDF-2 (2008) powder diffraction databases. The microhardness was measured with an automatic microhardness tester (DM-8B, Affri) using a Vickers test with a $300 \mathrm{~g}$ test load. Indentation was carried out on cross-sections of the samples of the coatings; the distance between the indents was $20 \mu \mathrm{m}$. On average, 10 tests were used as an indicator of coating hardness. The tribological evaluations of the coated substrates under dry conditions were performed using a ball on disc tribometer that was manufactured by CSM Instruments (Switzerland) according to ASTM wear testing standard G-99. All tests were performed at $25{ }^{\circ} \mathrm{C}$ with a relative humidity of approximately $50 \%$. A $6 \mathrm{~mm}$ in diameter sapphire ball was used as a counter body. Specimens from all series were tested under a $6 \mathrm{~N}$ normal load, a radius of the wear circle of $5 \mathrm{~mm}$, a $0.15 \mathrm{~m}-1$ sliding speed and a total sliding distance of $1200 \mathrm{~m}$. During testing the friction coefficient was recorded as a function of the sliding distance. The total wear volume was calculated by measuring the track cross-sectional area with a stylus profilometer (Taylor-Hobson) at ten different locations along the wear track. The ASTM G-99 standard determines the amount of wear by measuring the appropriate linear dimensions of both specimens (ball and disk) before and after the test [9].

All of the obtained samples are characterized by almost the same microstructures, microhardness and wear resistance. Arbitrary selected data are presented in the paper.

\section{Results and Discussion}

As a result of high-temperature annealing of the alumina powder was significantly increased content of the $\alpha$ $\mathrm{Al} 2 \mathrm{O} 3$ phase in the powder $(5.96 \%$ versus $65.44 \%$ after high-temperature annealing, respectively).

The thickness of the deposited coatings from the heat-treated alumina powder it was the within $\sim 150 \mu \mathrm{m}$ (porosity $\sim 1.5-2 \%$ ). Figure 1 shows the electron microscopy studies of the microstructure of the transverse sections of the alumina coatings obtained from the heat-treated alumina powder.

The dense coating was formed through the intensive plastic deformation resulting from the impact of a particle moving with high velocity and the tamping effect on the source side of the following particles. The interface between the coating and the substrate had no visible macro defects. 


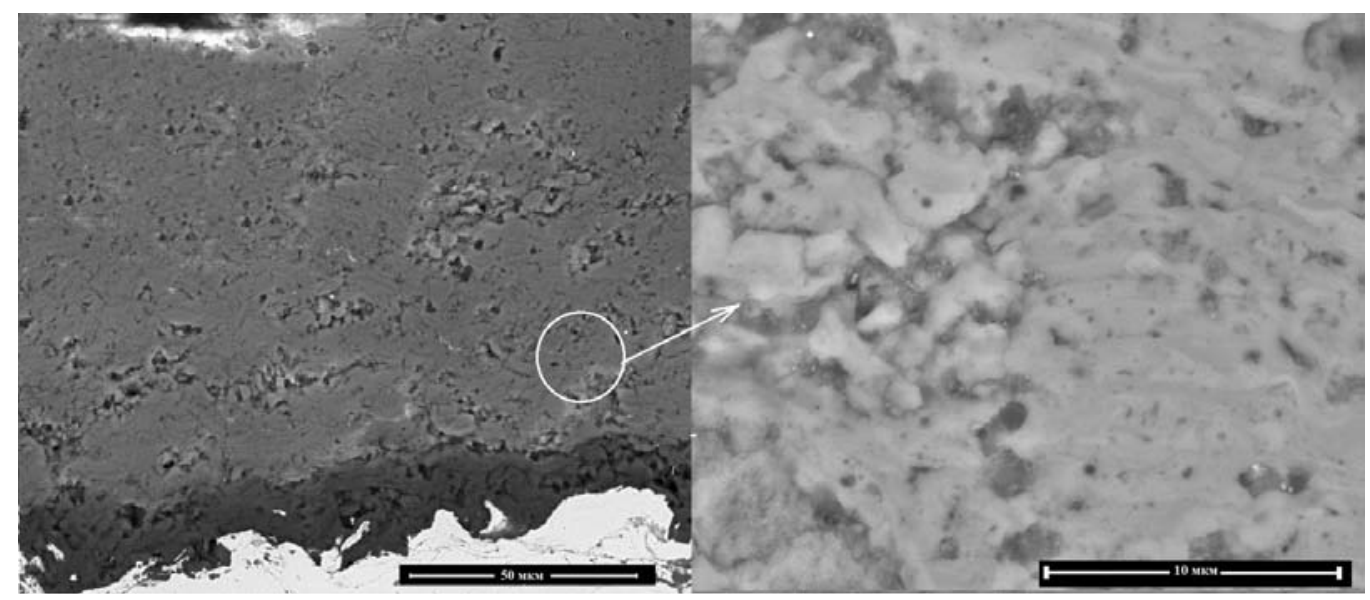

Fig. 1 Microstructure of the alumina powder coating

Figure 2 shows X-ray pattern of the alumina coatings from the heat-treated powder. It is obvious that $\alpha-\mathrm{Al} 2 \mathrm{O} 3$ with a cubic lattice $(73.86 \%)$ is the predominant phase in the coatings. This result may be of considerable interest, especially for dielectric applications. The XRD studies also indicated a small amount (22.34\%) of $\gamma-\mathrm{Al} 2 \mathrm{O} 3$ phase with a hexagonal lattice and impurity phase of $\mathrm{TiO} 2$ (rutile, $3.8 \%)$.

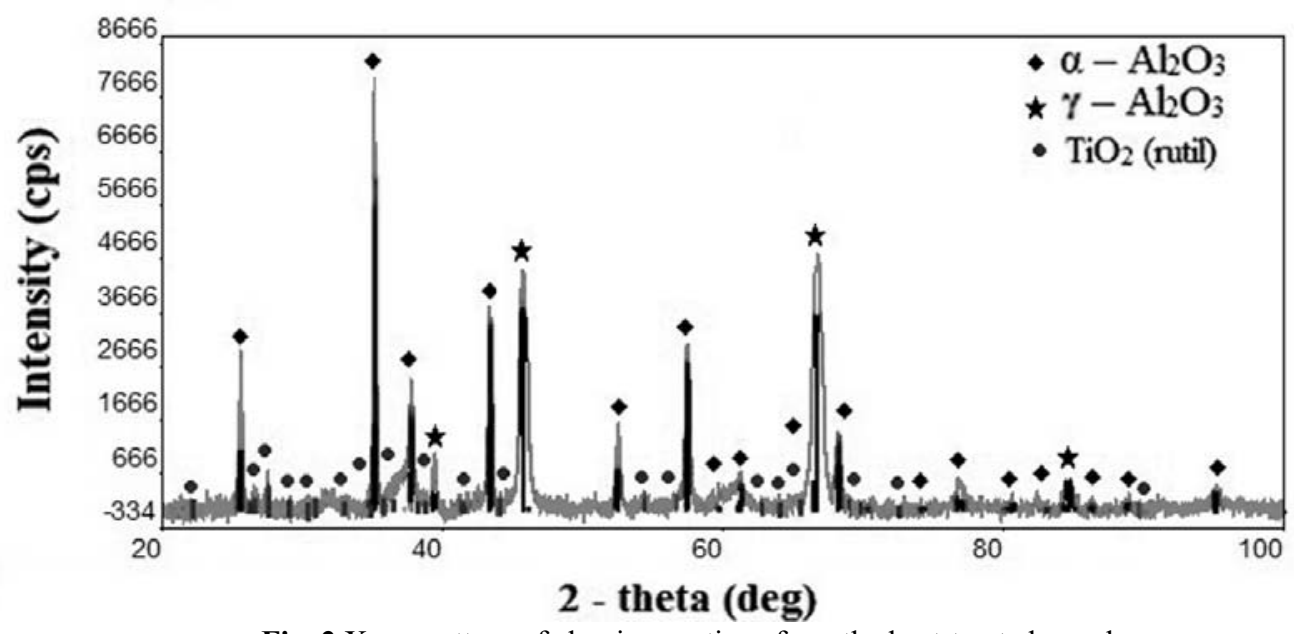

Fig. 2 X-ray pattern of alumina coatings from the heat-treated powder

The wear factor of the alumina coatings from the heat-treated powder was $5.06 \times 10-4 \mathrm{~mm} 2 /(\mathrm{N} \cdot \mathrm{m})$. The wear factor of the steel substrate was $35.36 \times 10-5 \mathrm{~mm} 2 /(\mathrm{N} \cdot \mathrm{m})$, of the ceramic coating of the alumina powder without the high temperature treatment $-4.40 \times 10-4 \mathrm{~mm} 2 /(\mathrm{N} \cdot \mathrm{m})$.

The microhardness of the coatings from the heat-treated alumina powder was $1280 \pm 30 \mathrm{HV} 0.3$ against the usual average hardness of steel $250 \pm 10 \mathrm{HV} 0.3$. The microhardness of the coatings of the alumina powder without the high temperature treatment was $1100 \pm 25$ HV0.3

The high microhardness of the coating of the heat-treated alumina powder attributed with to a phase composition. In reference [10] it is shown that the higher the proportion of $\alpha-\mathrm{Al} 2 \mathrm{O} 3$, the greater of the microhardness of the resulting coatings. The results of hardness comparable with the previously obtained results [4] for the powder coating of Amperit 740 based on $\alpha$ $\mathrm{Al} 2 \mathrm{O} 3$.

\section{Summary}

In this study, multi-chamber detonation sprayer (MCDS) was applied for deposition of alumina powder coatings on steel substrate. The alumina coatings made from the alumina powders were heat treated on air at $1000^{\circ} \mathrm{C}$. It was found that the high temperature treatment of the alumina powder contributes to a significant increase in $\alpha-\mathrm{Al} 2 \mathrm{O} 3$ phase $(5.96 \%$ versus $65.44 \%$ after high-temperature annealing, respectively). The microstructure and properties of the alumina powder coatings were investigated. MCDS has provided the conditions for formation from available and inexpensive raw materials a dense ceramic layer with a porosity of less than $2 \%$, hardness of $1280 \pm 30 \mathrm{HV} 0.3$ and wear factor was $5.06 \times 10-4 \mathrm{~mm} 2 /(\mathrm{N} \cdot \mathrm{m})$.

\section{Acknowledgments}

The study was financial supported by the Russian Science Foundation, under grant No 15-19-00189. All of studies 
were carried out by the scientific equipment of the joint research center "Diagnostics of structure and properties of nanomaterials" of Belgorod National Research University with is financially supported with Ministry of Science and Education of RF under project № 14.594.21.0010, unique code RFMEFI59414X0010.

\section{References}

1. F.L. Toma, L.M. Berger, et.al. Therm. Spray Technol. Vol. 20(1-2) (2011), p. 195.

2. P.A. Dearnley, et.al. Therm. Spray Technol. Vol. 2 (2003), p. 311.

3. N.N. Ault, et.al: Am. Ceram. Soc. Vol. 40 (1957), p. 69.

4. W. Schatt, K Wieters, et.al: Technologie und Werkstoffe; Springer: Berlin, Germany (2007).
5. M.G. Kovaleva, M.S. Prozorova, et.al: Russian Metallurgy (Metally).Vol. 4 (2014), p. 275

6. M.G. Kovaleva, Yu.N. Tyurin, et.al: Surf. Coat. Technol. Vol. 232 (2013), p. 719.

7. N.Ya. Vasilik, Yu. N. Tyurin, O.V. Kolisnichenko, RU. Patent 2,506,341 (2012).

8. G.J. Moskal: Achieve. Mater. Manuf. Eng. Vol. 20 (1-2) (2007), p. 483

9. Standard test method for wear testing with a Pin-on-Disk apparatus, ASTM G99-05(2010), Book of ASTM Standards, American Soc. for Metals, 03.02, (2010), p. 6

10. T.C. Chou, T.G. Nieh, et.al: Scripta Met. Vol. 25 (10) (1991), p. 2203. 